\title{
Potential shielding for a positron emission tomography (PET) suite
}

\author{
Michelle E. Bresnahan ${ }^{1}$, Bijaya Shrestha² \\ 1. Department of Environmental Health and Safety, Missouri University of Science and Technology, Missouri, United \\ States. 2. Department of Electrical and Computer Engineering, Missouri University of Science and Technology, Missouri, \\ United States.
}

Correspondence: Bijaya Shrestha. Address: 215 EE Hall, Missouri S\&T, Rolla, MO. 65401. Telephone: 573-341-6068. Email: Shrestha@mst.edu.

Received: February 12, $2012 \quad$ Accepted: May 6, $2012 \quad$ Published: June 1, 2012

DOI : $10.5430 / j b g c . v 2 n 1 p 89$

URL: http://dx.doi.org/10.5430/jbgc.v2n1p89

\begin{abstract}
Due to the amount of radioisotopes needed for use in positron emission tomography scans, it is important to have a careful planning of procedures and design of such facilities. Using the Monte Carlo N-Particle Transport Code (MCNP), a potential suite for a positron emission tomography (PET) facility was designed. The design covered three different areas as required in a PET facility: the scan room, the waiting area, and the hot lab. The design used two different shielding options, lead and concrete. Both materials were found to be enough to lower dose rates below the public dose limits set by the U.S. Nuclear Regulatory Commission.
\end{abstract}

\section{Key words}

Tomography, Monte Carlo, Radiation dose, Simulation, Monte Carlo N-Particle Transport Code, Positron emission, Neutral particle transport, Medical imaging

\section{Introduction}

Positron emission tomography is a nuclear medicine imaging technology ${ }^{[1]}$. It employs the use of radioisotopes that decay by positron emission followed by annihilation phenomena resulting in coincident pair of photons with $0.511 \mathrm{MeV}$. These photons emerge in opposite directions. The photon detectors of a PET scanner are arranged around the patient in such a way as to be able to detect the pair of emitted photons simultaneously. After enough coincident photon events are collected, reconstruction by computer results an image with the information of the positron-emitting isotope distribution ${ }^{[2]}$. This image is generally paired with another type of computer tomography image, such as a computed axial tomography scan, and then used to create detailed views of metabolic functions within the human body. These images are used for detection of cancer cells and evaluation of coronary artery disease. Due to the amount needed of radioisotopes for PET, it is very important to have a careful planning and design of facilities. Particular shielding design is required due to exposure of workloads and potential occupancies of the facility. More often than not, the shield materials for a PET facility can be combined with common building materials (i.e. gypsum wallboard combined with lead). Additionally, shielding material can be incorporated into the building structure (i.e. concrete brick) to cut down on the cost of material needed ${ }^{[3]}$. 
For this work the MCNP code was used to design and calculate the amount of shielding needed for the facility. Since there is no PET facility available at Missouri S\&T for study, a contact was made with a health physicist at Washington University in St. Louis, $\mathrm{MO}^{[4]}$ as a result of which the floor plan and structural information were provided about the PET located at the Mallinckrodt Institute of Radiology (MIR) ${ }^{[5]}$ which is the basis of the PET suite modeled in MCNP for this work (see Figure 1).

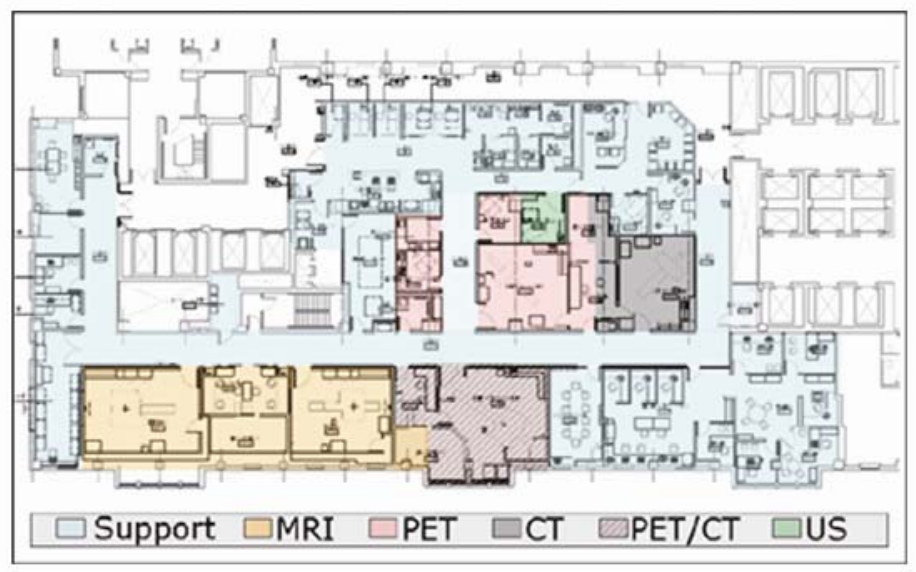

Figure 1. Floor plan of the Center for Clinical Imaging Research (CCIR) at MIR (http://ccir.wustl.edu/facilities/floorplan.shtml\#)

There were several assumptions made in the design of this facility which are discussed in more detail in the following sections. The main focus for design in this project was based on a facility able to utilize only one PET scanner.

\subsection{Facility}

The PET facility in this work was designed using MCNP and consists of a three room area: the hot lab, the waiting room, and the scanner room (see Figure 2).

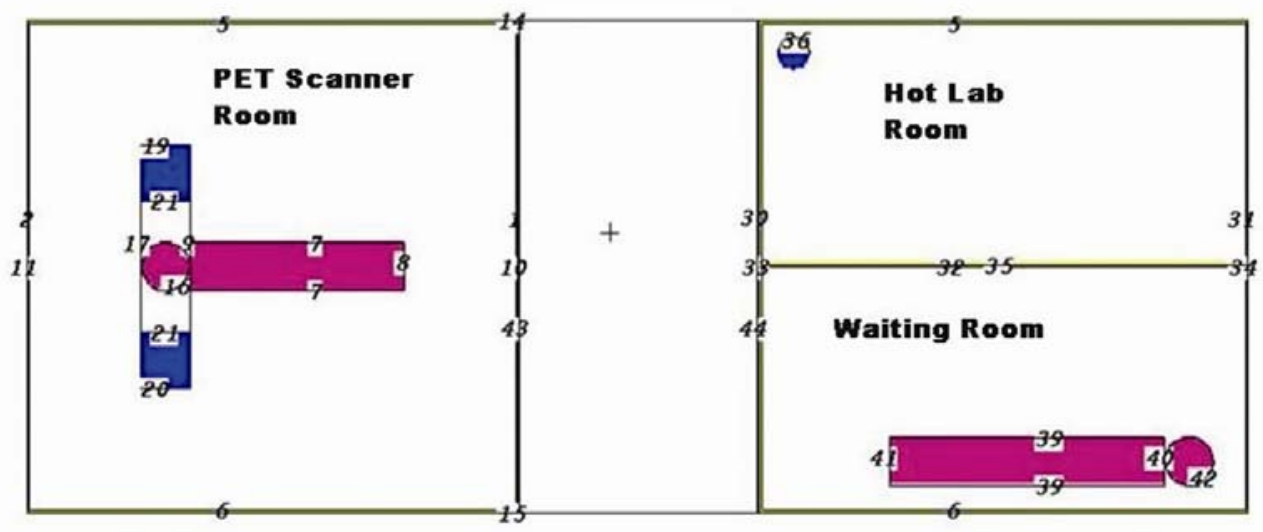

Figure 2. MCNP design of PET facility

The area that has the greatest potential for exposure is the hot lab. This is the area where the radioisotopes are stored, prepared, and injected into the patient. In this work, the facility was designed on the assumption that whole body scans would occur more than scans focused just on a particular area of the body, therefore only one injection room is modeled. The hot lab area design focused on conservative estimates in order to ensure that adequate shielding would be used. In this 
case, the hot lab area is a five foot by ten foot room with walls made of gypsum and a small cylindrical source located inside.

The patient waits in the waiting area after being injected with the radioisotope before they begin the PET scan. The wait is needed before beginning the scan to allow the radioisotope to collect in the area of the body it needs to. It is also important that the patient remain in relative seclusion during this time because the patient will be a source of radiation immediately after injection. For this design, the waiting area was designed as a five foot by ten foot room with walls made of gypsum and a person, temporarily considered a source, located inside.

The scanner room physically houses the PET scanner (see Figure 3). By the time patient comes to the scan room, the patient is no longer a valid source of radiation due to the relatively short half-life of the radioisotope injected; as total activity would have been reduced in the patient body. The physical scan area, where the exposures are expected to be the least for both the medical personnel and the people who occupy the surrounded areas, is a ten foot by ten foot room with walls made of gypsum containing the scanner and a radiating person, the source.

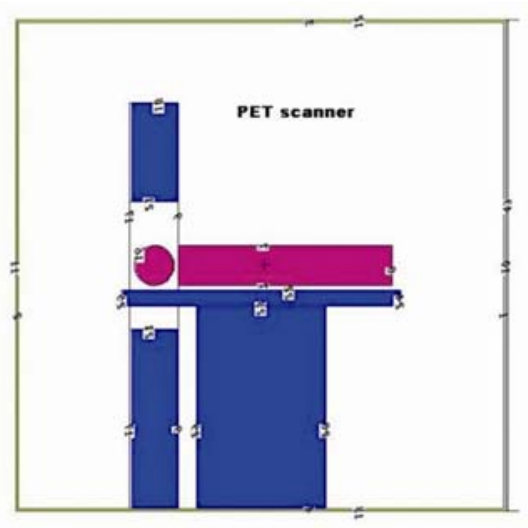

Figure 3. MCNP design of PET scanner

\subsection{Shielding}

The shielding for each area in the PET suite was determined placing a layer of material, either lead or concrete, outside a single wall of each room. Each unshielded wall showed an equal dose rate; therefore it was only necessary to experiment with one wall to determine appropriate shielding for all four. For the hot lab, the wall with the highest dose rate measured was selected to achieve the most conservative estimate.

\subsection{Source}

There were three sources used in this work, each one in a different room in the suite. In the scanner room the source was modeled as a 5'8" person, simulated by a cylinder of water, with a spherical head, also filled with water. The hot lab area contained a source modeled as an eight inch plastic vial to simulate the radioisotope before it was injected into the patient. The waiting area contained a source modeled as a 5'8” person, also simulated by a cylinder of water with a spherical head. All sources were designed to emit photon energy at $0.511 \mathrm{MeV}$.

\subsection{Workload \& workflow}

As previously stated, the PET suite was designed principally for whole body scans. The most widely used PET radiopharmaceutical is ${ }^{18} \mathrm{FDG}$ (18F-fluorodeoxyglucose), an analog of the body's metabolic energy source, glucose, used by brain tissue, malignant cancer cell, and other tissues ${ }^{[6]}$. For a whole body scan, the amount of injection ranges from 3 $\mathrm{mCi}$ to $15 \mathrm{mCi}^{[2]}$. In this work, the dose was assumed to be $12 \mathrm{mCi} \mathrm{of}{ }^{18} \mathrm{~F}$, to be injected into the person before the 
beginning of the scan. The facility would, however, receive a larger amount of the isotope in use if more than one scan is to be performed that day, and store it. Using syringes and dose calibrators, medical technologists would divide the larger amount of the isotope into the correct amounts to be injected into each patient receiving a PET scan. A total amount of 300 $\mathrm{mCi}$ of ${ }^{18} \mathrm{~F}$ was assumed to be delivered to the facility at the start of each day. The patient will be held for approximately one hour after injection to allow for isotope uptake into the body. The patient will undergo emission scans once the waiting period expires.

In this case, since only one scanner is in use at this facility, it will only be able to deal with one patient at a time. Assuming a nine hour day, the facility would only be able to handle eight patients per day at a maximum. This particular PET was designed as a conventional bismuth germanium scanner, taking approximately fifty minutes per whole body scan ${ }^{[2]}$. Since the annual number of nuclear medicine procedures has increased three-fold (from seven million to twenty million) between 1985 and 2005, a reasonable approach was to assume that the facility would remain busy throughout the year ${ }^{[7]}$. The facility would need to be taken out of service seven weeks each year for maintenance and calibration.

\section{Methodology: simulation parameters}

We developed an MCNP model of the PET facility, which consisted of the hotlab, waiting room, and scanning room with the patient modeled as a water-filled cylindrical phantom with a spherical head. All of the walls in the model were considered to be made of gypsum with half an inch thickness. Using combinatory, the geometry of the rooms and the patient were modeled and input to the program using cell and surface cards as required. The dimensions of the hotlab and the waiting room were modeled to be $5 \mathrm{ft}$ by $10 \mathrm{ft}$ where as that of the scanning room was $10 \mathrm{ft}$ by $10 \mathrm{ft}$. The patient was modeled as lying on the platform. These geometrical modeling are shown in Figures 2 and 3.

All of the sources including the plastic vial containing ${ }^{18} \mathrm{FDG}$ in the hotlab and the patient were all considered to emit $0.511 \mathrm{MeV}$ photons. Using importance card, a calculation optimization technique within MCNP, the simulation was optimized and dose deposited by the photons were tallied for million histories, so that the uncertainty in the dose calculations are below $1 \%$. The MCNP modeling was done to create a realistic situation. Therefore certain approximations were made for the sake of simplicity such as modeling the patient by a cylinder filed with water. In this regard, some of the limitations in our modeling are the following:

\subsection{Physics limitation}

${ }^{18} \mathrm{FDG}$ is considered solely as ${ }^{18} \mathrm{~F}$ as far as the radiation us considered. All sources are considered to emit $0.511 \mathrm{MeV}$ photons

\subsection{Design limitation}

Patient was modeled as a cylinder of water with a spherical head

\subsection{Radiation Protection}

\section{Regulations}

The U.S. Nuclear Regulatory Commission (NRC) protects the health and well-being of persons who could potentially be exposed to ionizing radiation occupationally. These people are often willing to be exposed to minimal amounts of radiation for their occupation. The NRC also protects members of the public from radiation found in licensed activities ${ }^{[8]}$. NRC regulations limit exposure to ensure that no individual will receive more than 100 millirems per year from licensed operations ${ }^{[9,10]}$. Additionally, the NRC requires that the dose rate in areas accessible to members of the public not exceed 2 mrem in any given hour. Radiation workers are limited to an exposure of five rem per year. Along with the regulations, the ALARA (as low as reasonably achievable) guideline is a radiation exposure concept intended to encourage protection practices. 


\section{Results and discussion}

\subsection{PET scan room}

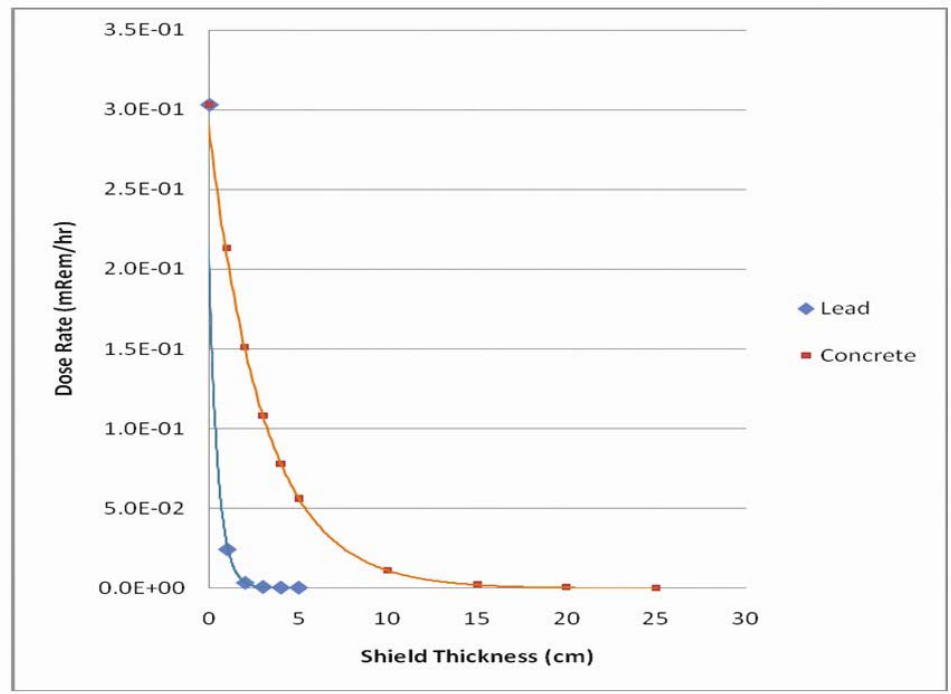

Figure 4. Dose rates on the outside of the PET scan room walls using lead and concrete has shielding material in varying thickness

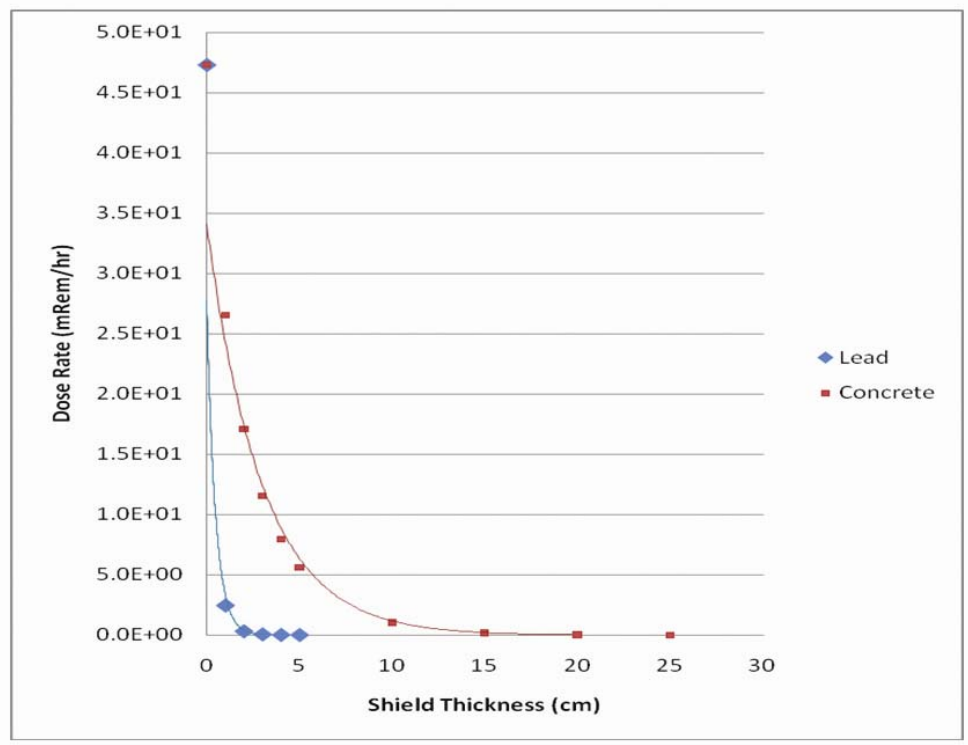

Figure 5. Dose rates on the outside of the Hot lab room walls using lead and concrete has shielding material in varying thickness

By the time the patient reaches the PET scan room, the $12 \mathrm{mCi}$ dose of ${ }^{18} \mathrm{~F}$ they were originally injected has decayed to about $8.22 \mathrm{mCi}$. This activity was used to calculate the exposure on the outsides of the PET room walls. With no shielding in place, the dose rate is below the 2 mrem per hour limit set in the NRC regulations. It is important to note, however, that while the dose rate is within NRC regulations, when the workload of the facility is taken into account, the exposure rates 
quickly reach greater than one hundred mrem per year. The dose with no shielding is approximately 0.3 mrem per hour. If eight patients are seen per day, five days per week, forty five weeks each year, the total dose rate is approximately 540 mrem per year; over five times the limit. An unshielded facility could process no more than seven people per day, once a week. If one centimeter of lead shielding is used, the dose rate falls below regulatory limits both hourly and annually.

As seen from Figures 4 and 5, for $5 \mathrm{~cm}$ of concrete, dose rate of $\sim 5.10^{-2} \mathrm{mRem} / \mathrm{hr}$ was found when $8.22 \mathrm{mCi}$ was used. When $300 \mathrm{mCi}$ is used, dose rate of $\sim 5.10^{0} \mathrm{mRem} / \mathrm{hr}$ was found for the same $5 \mathrm{~cm}$ thickness of concrete. The results are proportional to fluency/activity of the source (ratio of $10^{2}$ ), which is quite reasonable.

\subsection{Hot lab room}

The hot lab room, where the radioisotopes are delivered and stored, presents the biggest shielding challenge and greatest amount of radiation exposure. For this project, it was assumed that approximately $300 \mathrm{mCi}$ of ${ }^{18} \mathrm{~F}$ would be stored in the hot lab. The amount can then be separated out into individual syringes for injection into patients. With no shielding in place, the dose rate on the outside of the walls was calculated to be approximately $47.32 \mathrm{mrem} / \mathrm{hr}$, far exceeding the limits set by the NRC.

Shielding in this area is a must. It was determined that using two inch lead brick to line the walls of this area would lower the dose rate to within regulatory limits. Eight inch concrete bricks would also be sufficient.

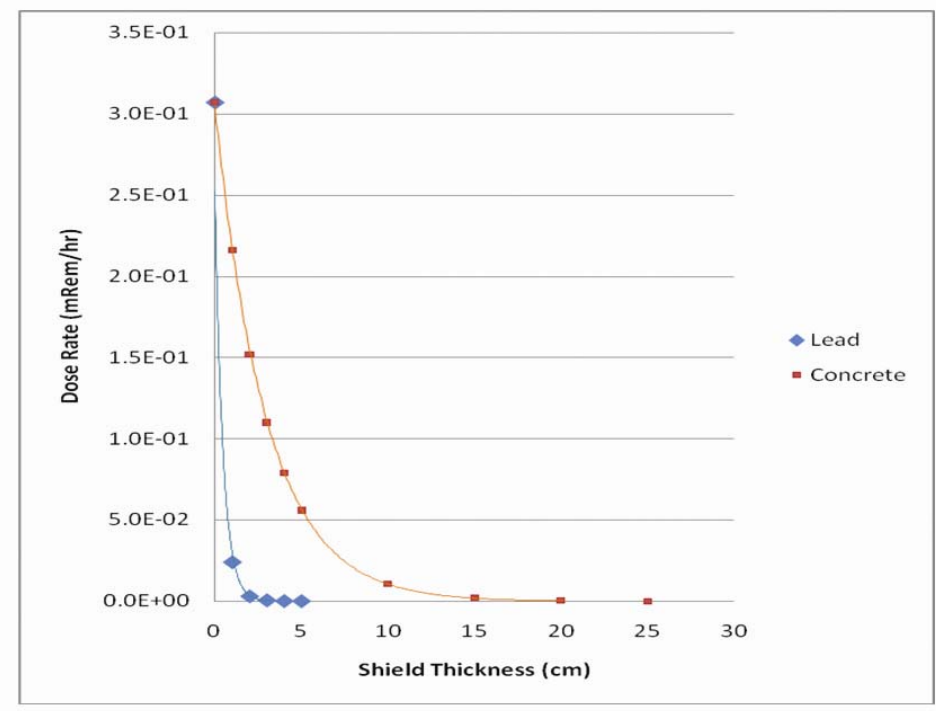

Figure 6. Dose rates on the outside of the Holding room walls using lead and concrete has shielding material in varying thickness

\subsection{Holding room}

The shielding for the holding room was calculated using the same amount injected into the patient, $12 \mathrm{mCi}$ of ${ }^{18} \mathrm{~F}$. Dose rates in this area are very similar to those in the PET scan room. With no shielding, the dose rate on the outside of the holding room wall about $0.31 \mathrm{mrem} / \mathrm{hr}$, again is below the regulated hourly limit. However, after the workload of the facility is taken into consideration, the dose rate is found to be above the annual exposure limit. The MCNP design confirmed that one centimeter of lead sheeting was sufficient to shield the area to within acceptable limits. Also, only two inches of concrete block is necessary to shield within acceptable limits. 


\section{Conclusion}

Both lead and concrete are sufficient to shield a PET scan facility. The most economical decision when deciding how to shield a PET facility would be to either design or pick a location that already has shielding material in place. For example, most buildings are built with concrete block exterior walls. If the PET suite could be located in an area where it uses an outer wall, the concrete from the building should be sufficient to shield within acceptable dose limits. Ideally, the hot lab would be placed in a corner room where it can utilize two concrete walls, considerably cutting down the cost of materials like lead needed to shield the inner walls. The PET scan room exhibited the smallest dose rate and therefore, could be placed in a central location. Since the holding room and the hot lab need to be in close proximity, the holding room would also utilize a concrete outer wall.

\section{References}

[1] "Positron Emission Tomography - Computed Tomography (PET/CT)." Radiology Info. 11 Sept. 2008. Radiological Society of North America [Internet]. 2008. Available from: http://www.radiologyinfo.org/en/info.cfm?pg=pet\&bhcp=1.

[2] Anderson, Jon A., and Dana Mathews. Site Planning and Radiation Safety in the PET Facility. Ts. The University of Texas Southwestern Medical Center at Dallas, Dallas, TX, 2002.

[3] Methe, Brian M. "Shielding Design for a PET Imaging Suite: A Case Study." Operation Radiation Safety. 2004 ; S83-88.

[4] Szatkowski, Dan. "Information on PET." E-mail to the author. 16 Oct. 2008.

[5] "Floor plan for the CCIR." Center for Clinical Imaging Research. 8 May 2007. Washington University in St. Louis. 11 Dec. 2008 Available from: http://ccir.wustl.edu/facilities/floorplan.shtml.

[6] Erdman, Mike, Steve King, and Ken Miller. "Recent Experiences with Shielding a PET/CT Facility." Operational Radiation Safety 87 (2004); S37-39.

[7] Zanzonico, Pat, Lawrence Dauer, and Jean St. Germain. "Operational Radiation Safety." Health Physics. 2008: 554-70. PMid:18849690 http://dx.doi.org/10.1097/01.HP.0000327651.15794.f7

[8] Coker, Audra L. "PET/CT Shielding Design Comparisons." Thesis. College Station, Texas

[9] Nuclear Regulation Commission, Code of Federal Regulations 10CFR20.1201, “Occupational dose limits for adults,” (U.S Government Printing Office, 1999).

[10] Nuclear Regulatory Commission, Code of Federal Regulations 10CFR20.1301, "Dose limits for individual members of the public,” (U.S Government Printing Office, 1999). 